\title{
Almond "Appetizer" Effect on Glucose Tolerance Test (GTT) Results
}

\author{
Michael A. Crouch, MD, MSPH, and Robert T. Slater III, MD, MPH
}

Background: The extent to which glucose intolerance can be acutely improved with dietary modification is unclear. The purpose of this study was to test the effect of ingesting a low-calorie almond preload ("appetizer") 30 minutes before oral glucose tolerance testing in glucose-intolerant individuals without diabetes.

Methods: Twenty adults with prediabetes or isolated 1-hour glucose $\geq 160 \mathrm{mg} / \mathrm{dL}$ underwent 2 fasting oral glucose tolerance tests (GTTs) -1 standard GTT and 1 GTT 30 minutes after eating a half ounce (12) of dry-roasted almonds. Fourteen participants met 1 or more prediabetes diagnostic criteria; 6 had only elevated 1 -hour glucose $\geq 160 \mathrm{mg} / \mathrm{dL}$.

Results: The mean 1-hour plasma glucose after the almond preload was $37.1 \mathrm{mg} / \mathrm{dL}$ (19.4\%) lower $(154.6$ vs $191.7 ; P<.001)$ than in the standard GTT. The almond preload reduced the area under the glucose curve by $15.5 \%(P<.001)$. Eight individuals had a marked hypoglycemic effect (glucose reduced by 45 to $110 \mathrm{mg} / \mathrm{dL}) ; 4$ had a moderate hypoglycemic effect $(22-32 \mathrm{mg} / \mathrm{dL})$.

Conclusion: A low-calorie almond "appetizer" showed promise as an option for decreasing postprandial hyperglycemia in individuals with prediabetes or isolated 1-hour postprandial hyperglycemia. Further study is needed to confirm and refine the role of such a premeal appetizer in the self-care of prediabetes. (J Am Board Fam Med 2016;29:759-766.)

Keywords: Area Under Curve, Blood Glucose, Eating, Energy Intake, Fasting, Food Habits, Glucose Intolerance, Glucose Tolerance Test, Hyperglycemia, Prediabetic State, Prunus dulcis, Self-Care

Nearly 30 million Americans (almost 10\% of adults) had diabetes in 2012 (mostly type 2), and another 86 million Americans (almost 30\% of adults) had prediabetes. ${ }^{1}$ Patients known to have prediabetes are at high risk for developing diabetes. ${ }^{2}$ Although exercise, weight control, and hypoglycemic medications have been shown to prevent progression from prediabetes to diabetes, ${ }^{3}$ many patients are unwilling or unable to make good use of these options.

Progression from normal glucose tolerance to diabetes is associated with a progressive decrease in

This article was externally peer reviewed.

Submitted 21 April 2016; revised 23 August 2016; accepted 26 August 2016.

From the Memorial Family Medicine Residency, Sugar Land, TX.

Funding: This study was funded by a grant from the Texas Academy of Family Physicians Foundation.

Conflict of interest: none declared.

Corresponding author: Michael A. Crouch, MD, MSPH, Memorial Family Medicine Residency, 14023 Southwest Freeway, Sugar Land, TX 77478 (E-mail: michael.crouch46@ gmail.com). acute insulin response to ingested carbohydrates and a variable reduction in insulin sensitivity. Both dysfunction and loss of pancreatic $\beta$-cells contribute to glucose intolerance. ${ }^{4}$ Toxic effects of hyperglycemia on $\beta$-cells contribute to the progression from impaired glucose tolerance to diabetes. ${ }^{5}$

One of the main causes of postprandial hyperglycemia is reduced or delayed insulin release in response to nutrient ingestion. ${ }^{6}$ During an oral glucose tolerance test (GTT), first-phase insulin response begins within 5 minutes after glucose ingestion and lasts for about 30 minutes. With prediabetes, some individuals have reduced or absent first-phase insulin response, whereas others have normal first-phase insulin concentrations but do not maintain normal glucose concentrations because of reduced insulin sensitivity. The second phase of acute insulin response begins 10 to 15 minutes after glucose ingestion and persists while the hyperglycemic stimulus is present. ${ }^{6}$

During a GTT, glucose and insulin concentrations typically peak at 30 to 45 minutes. Glucose 
intolerance at 1 hour on the GTT has serious clinical implications, even when the 2-hour glucose is $<140 \mathrm{mg} / \mathrm{dL}$. Elevated 1-hour glucose concentrations are the earliest, and often the only, reflection of impaired first-phase insulin release. Glucose intolerance at 1 hour seems to be the earliest physiologic indicator of an individual's proneness to type 2 diabetes. ${ }^{6}$ One-hour GTT >155 mg/dL predicts future development of diabetes better than abnormal fasting or 2-hour GTT values. ${ }^{7}$

Lifestyle approaches to reducing hyperglycemia have focused mainly on improving insulin sensitivity (via exercise and weight loss) or limiting total carbohydrate intake. The extent to which glucose intolerance can be improved with dietary modification is unclear, but several studies have shown that manipulating the timing of part of one's caloric intake can improve glucose tolerance.

Heacock et $\mathrm{al}^{8}$ found that ingesting $10 \mathrm{~g}$ of fructose 30 or 60 minutes before eating a highcarbohydrate test meal reduced the positive incremental area under the glucose curve by $25 \%$ to $27 \%$. A soya-yogurt snack (30 g of soybeans and $75 \mathrm{~g}$ of yogurt) 2 hours before breakfast reduced the postprandial glucose increment by almost $40 \%$. ${ }^{9}$ Josse et $\mathrm{al}^{10}$ and Jenkins et $\mathrm{al}^{11}$ showed a $21 \%$ to $42 \%$ reduction in peak postprandial hyperglycemia by adding 30 to $90 \mathrm{~g}$ of almonds to a test meal containing $50 \mathrm{~g}$ of carbohydrates. Tan and Mattes ${ }^{12}$ found that $43 \mathrm{~g}(1.5 \mathrm{oz})$ of almonds given as midmorning and midafternoon snacks mildly lowered postprandial serum glucose.

The purpose of this study was to test the effect of a low-calorie dietary preload (12 dry-roasted almonds, eaten 30 minutes in advance of a GTT) on GTT results in individuals with prediabetes and/or an elevated glucose concentration on a 1-hour GTT. The study hypothesis was that "priming the pancreatic pump" with a low-calorie "appetizer" 30 minutes before GTT would significantly decrease the hyperglycemic response at 1 hour in glucose-intolerant individuals who do not have diabetes. In theory, it would do so by boosting insulin secretion before ingesting the main caloric load. A prestudy analysis of glucose-intolerant patients' GTTs at the study site found that the mean 1-hour GTT value was $40 \mathrm{mg} / \mathrm{dL}$ higher than the 2-hour GTT value (185 vs $145 \mathrm{mg} / \mathrm{dL}$ ), showing more room for improvement in the 1-hour than the 2-hour value.
The one-half ounce (14.2 g) almond snack given in this study contained $84 \mathrm{kcal}$, including $3 \mathrm{kcal}$ from $0.7 \mathrm{~g}$ carbohydrate, $12 \mathrm{kcal}$ from $4 \mathrm{~g}$ protein, and $68 \mathrm{kcal}$ from $7.5 \mathrm{~g}$ fat (mostly polyunsaturated, averaging $65 \%$ omega-6 linoleic acid and 27\% omega-3 $\alpha$-linolenic acid). ${ }^{13}$ If the study results support the hypothesis, glucose-intolerant individuals who respond well to the almond preload and regularly ingest such a premeal appetizer might (1) have lower peak glucose concentrations after eating, and (2) be hyperglycemic less of the time.

Compared with published studies of the effects of almonds on glucose tolerance, this study entailed eating a smaller amount of almonds ( $1 / 2$ vs $1-3 \mathrm{oz})$ and with different timings: 30 minutes before, rather than 2 hours before or during, main calorie consumption. Prefeeding the low-calorie (84 kcal) almond serving with "appetizer" timing may produce a beneficial effect on glucose intolerance similar to that seen in studies of prefeeding fructose (44 kcal $)^{9}$ or soya-yogurt $(180 \mathrm{kcal}){ }^{10}$

\section{Methods}

In this crossover experimental study, each participant served as their own control. Inclusion criteria were age 18 to 90 years, prediabetic level of $\mathrm{HbA}_{1 \mathrm{c}}$ (5.7 to $6.4 \%)$ and elevated ( $\geq 160 \mathrm{mg} / \mathrm{dL}) 1$-hour glucose on a standard fasting 2-hour GTT. Exclusion criteria included diabetes diagnosis (fasting GTT result $>125 \mathrm{mg} / \mathrm{dL}$ and/or 2-hour result $>200 \mathrm{mg} / \mathrm{dL}$ ); currently taking any medication affecting glucose concentration (including insulin, other hypoglycemic medications, and oral or injected corticosteroids); history of almond allergy; inability to render informed consent because of cognitive or other impairment; inability or unwillingness to complete 2 oral GTTs within 4 weeks; and severe acute or unstable chronic illness.

Study participants, comprising a convenience sample, were initially identified by searching the study site's electronic medical record (Centricity) using the above-mentioned inclusion criteria. Potentially eligible patients were contacted via E-mail or regular mail, then by telephone, to elicit their interest in participating and to screen for the above-mentioned exclusion criteria. Those who still seemed to be eligible and expressed interest were scheduled for an initial study visit, when written informed consent was obtained. Those whose 1-hour result on a standard GTT was $>160 \mathrm{mg} / \mathrm{dL}$ 
were invited to complete a second GTT (after almond ingestion).

Each full study participant underwent 2 fasting oral GTTs, most of them 2 to 7 days apart. One was a standard 75-g GTT, and the other was a GTT that began 30 minutes after ingesting a half ounce of dry-roasted almonds (12 average-sized almonds) and drinking an 8-ounce glass of tap water. Each almond load was weighed as exactly half an ounce on a food scale, and it was ingested in a mean time of 3.2 minutes. Venous blood was sampled for serial measurements of plasma glucose at baseline, and at 1 and 2 hours after each $75-\mathrm{g}$ glucose load. Initially the order of the standard GTT and the almond GTT was varied randomly to control for the sequence effect. However, since a large percentage of initial enrollees did not meet the inclusion criterion of 1-hour glucose $\geq 160 \mathrm{mg} /$ $\mathrm{dL}$, the standard GTT was done first in 17 of the 20 participants.

To minimize the variability of GTT results, participants were asked to eat as they usually did throughout the study. Participants were asked to refrain from vigorous physical activity for 8 hours before each GTT and to minimize their physical activity during each GTT. Participants completed the 14-item Perceived Stress Scale ${ }^{14}$ and a 24-hour food, alcohol, and activity record the day before each GTT.

The study was conducted in a university-affiliated, community-based family medicine residency program clinic. Blood was drawn by 1 of several phlebotomists in the on-site laboratory and sent to an outside laboratory for analysis. Blood samples from 16 of the participants were analyzed by the affiliated hospital laboratory; blood samples from 4 participants were analyzed by 1 commercial laboratory that the patients' managed Medicare insurance required.

A sample size calculation used the standard deviation for the 1 -hour glucose $(33 \mathrm{mg} / \mathrm{dL})$ seen in the GTT results of 70 patients who would have been eligible for this study. With an $\alpha$ of 0.05 , power of 0.80 , and 2-sided statistical significance testing, an estimated 16 participants would be needed to detect a medium anticipated effect size of 0.6 standard deviation $(20 \mathrm{mg} / \mathrm{dL}$ lower mean 1-hour GTT result produced by the almond preload).

This study was approved by the University of Texas-Houston Institutional Review Board. Each participant received a \$50 VISA gift card after the first GTT. If they qualified for the almond GTT, they received another $\$ 50$ gift card after completing the second test.

\section{Data Analysis}

The primary dependent variable was the mean difference in plasma glucose 1 hour after a 75 -g glucose challenge with versus without the almond preload. The Student $t$ test and area under the curve (AUC) were used to analyze the difference between standard 75-g GTT results and GTT results following the almond preload, as well as potential confounders. Statistical significance was set at $P<$ .05 (2-sided). Food records were analyzed using the US Department of Agriculture National Nutrient Database for Standard Reference, ${ }^{13}$ when possible, or from the more item-specific MyFitnessPal.com database ${ }^{15}$ when foods were not clearly identifiable in the US Department of Agriculture National Database. All statistical analyses were performed with MedCalc software version 13.2.2.0 (MedCalc Software, Ostend, Belgium).

\section{Results}

Of the 53 patients who enrolled in the study, 20 met the inclusion/exclusion criteria and completed the study. Eight never did the standard GTT, 2 did the standard OGTT but not the almond GTT, and 23 did not qualify for the almond GTT. Of the nonqualifiers, 17 had a 1-hour glucose $<160$ $\mathrm{mg} / \mathrm{dL}$ and 6 were diagnosed with diabetes. The mean interval between the 2 GTTs was 10.5 days (median, 7 days).

The mean age of the 20 study completers was 60.8 years (median, 66 years; range $18-90$ years); 13 were men, 7 were women. Self-identified race/ ethnicity was non-Hispanic white in 11 completers, Hispanic in 6, Asian in 2, and African American in 1. The mean body mass index (BMI) of study completers was $29.5 \mathrm{~kg} / \mathrm{m}^{2}$ (median, $28.9 \mathrm{~kg} / \mathrm{m}^{2}$; range, $\left.21-38 \mathrm{~kg} / \mathrm{m}^{2}\right) ; 8$ were obese $\left(\mathrm{BMI} \geq 30 \mathrm{~kg} / \mathrm{m}^{2}\right), 8$ were overweight (BMI $25-29 \mathrm{~kg} / \mathrm{m}^{2}$ ), and 4 were in the ideal weight range (BMI $20-24 \mathrm{~kg} / \mathrm{m}^{2}$ ). The mean $\mathrm{HbA}_{1 \mathrm{c}}$ level was $6.0 \%$.

The mean standard GTT results were 100.0 $\mathrm{mg} / \mathrm{dL}$ fasting; $191.7 \mathrm{mg} / \mathrm{dL}$ at 1 hour; and 138.0 $\mathrm{mg} / \mathrm{dL}$ at 2 hours (Table 1 ). Fourteen met 1 or more prediabetes diagnostic criteria; 5 had a 2 -hour glucose $\geq 140 \mathrm{mg} / \mathrm{dL}$ as their only prediabetes cri- 
Table 1. Mean Glucose Tolerance Test Results and Potential Confounders

\begin{tabular}{|c|c|c|c|c|}
\hline & Standard GTT & Almond GTT & $\begin{array}{l}\text { Difference between Standard and } \\
\text { Almond GTT, mg/dL (\%) }\end{array}$ & $\begin{array}{l}\text { Statistical Significance } \\
\text { (2-Sided } P \text { Value) }\end{array}$ \\
\hline \multicolumn{5}{|l|}{ Glucose (mg/dL) } \\
\hline Fasting & $100.0(9.3)$ & $97.1(8.3)$ & $-2.9(2.9)$ & .14 \\
\hline $1-\mathrm{hr}$ & $191.7(20.6)$ & $154.6(37.8)$ & $-37.1(19.4)$ & $<.001$ \\
\hline $2-\mathrm{hr}$ & $138.0(35.4)$ & $118.5(27.6)$ & $-19.5(14.1)$ & .02 \\
\hline Carbohydrate intake $(\mathrm{g})$ & $228.1(88.6)$ & $195.1(73.3)$ & $-33.0(14.5)$ & .18 \\
\hline \multicolumn{5}{|l|}{ Physical activity (minutes) } \\
\hline Mean (SD) & $94.6(125.4)$ & $117.9(170.7)$ & $+23.3(24.6)$ & .15 \\
\hline Median & 50 & 45 & $-5(10)$ & NA \\
\hline Perceived stress level & $17.5(5.6)$ & $15.9(4.9)$ & $-1.6(9.1)$ & .20 \\
\hline
\end{tabular}

Data are mean (standard deviation [SD]) unless otherwise indicated. Bold values indicate statistically significant difference. GTT, glucose tolerance test; NA, not available.

terion, 4 had a fasting glucose of 100 to $125 \mathrm{mg} / \mathrm{dL}$ as their only prediabetes criterion, and 5 had both fasting glucose of 100 to $125 \mathrm{mg} / \mathrm{dL}$ and 2-hour glucose of 140 to $199 \mathrm{mg} / \mathrm{dL}$. Six individuals had elevated 1-hour glucose $\geq 160 \mathrm{mg} / \mathrm{dL}$ as their only abnormal glucose value.

Thirty minutes after almond ingestion, the baseline GTT glucose was $2.9 \mathrm{mg} / \mathrm{dL}$ lower $(P=.14)$ than the standard GTT fasting glucose (Table 1, Figure 1). The mean 1-hour glucose was 37.1 $\mathrm{mg} / \mathrm{dL}(19.4 \%)$ lower $(P<.001)$ after almond ingestion than in the standard GTT. All participants' GTT values are shown in Table 2. Eight individuals showed a marked hypoglycemic effect 45 to $110 \mathrm{mg} / \mathrm{dL}$ (24\% to $58 \%$ ) lower and 4 showed a lesser hypoglycemic effect of 22 to 32 $\mathrm{mg} / \mathrm{dL}(12 \%$ to $17 \%)$ for the 1 -hour glucose value.

Figure 1. Mean results of the almond glucose tolerance test (GTT) vs a control GTT in glucoseintolerant patients $(n=20)$.

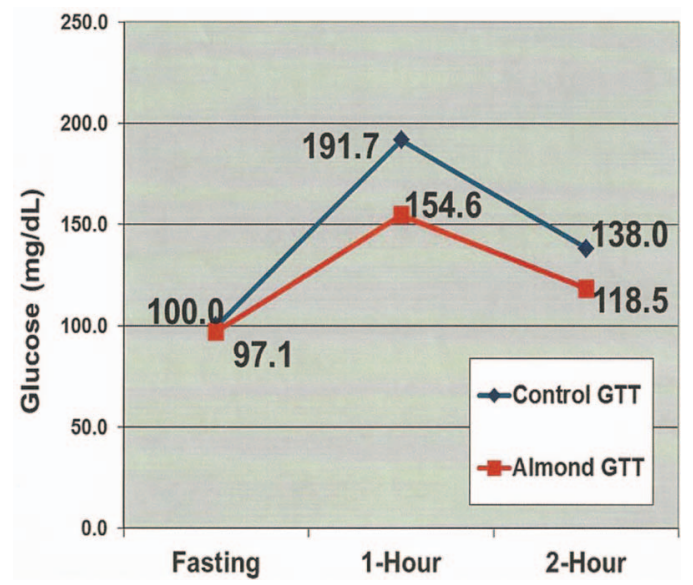

The responses of the 4 best responders are shown in Figure 2.

The mean 2-hour glucose difference was 19.5 $\mathrm{mg} / \mathrm{dL}(14.1 \% ; P=.02)$. After almond ingestion, individual 2-hour concentrations were markedly lower by 78 to $96 \mathrm{mg} / \mathrm{dL}$ ( $41 \%$ to $50 \%$ ) in 3 , moderately lower by 20 to $39 \mathrm{mg} / \mathrm{dL}$ ( $10 \%$ to $20 \%)$ in 6 , and not significantly different in 11 participants. Of the 8 participants who did not show a statistically significant effect at 1 hour, 2 were moderately lower ( 24 to $39 \mathrm{mg} / \mathrm{dL}$ ) 2 hours after the almond preload.

Table 2. Individual Glucose Tolerance Test Results (mg/dL)

\begin{tabular}{|c|c|c|c|c|c|c|}
\hline \multirow[b]{2}{*}{ Participant } & \multicolumn{2}{|c|}{ Fasting Glucose } & \multicolumn{2}{|c|}{ 1-Hour Glucose } & \multicolumn{2}{|c|}{ 2-Hour Glucose } \\
\hline & Standard & Almond & Standard & Almond & Standard & Almond \\
\hline 1 & 92 & 94 & 178 & 91 & 106 & 93 \\
\hline 2 & 104 & 100 & 214 & 192 & 156 & 173 \\
\hline 3 & 83 & 86 & 179 & 87 & 182 & 86 \\
\hline 4 & 102 & 106 & 194 & 170 & 152 & 139 \\
\hline 5 & 122 & 105 & 178 & 133 & 115 & 92 \\
\hline 6 & 97 & 87 & 169 & 164 & 86 & 91 \\
\hline 7 & 101 & 97 & 167 & 174 & 81 & 120 \\
\hline 8 & 114 & 117 & 208 & 105 & 179 & 101 \\
\hline 9 & 94 & 93 & 166 & 156 & 131 & 126 \\
\hline 10 & 97 & 97 & 230 & 216 & 191 & 167 \\
\hline 11 & 90 & 99 & 185 & 190 & 110 & 109 \\
\hline 12 & 97 & 96 & 201 & 152 & 116 & 86 \\
\hline 13 & 93 & 95 & 173 & 159 & 141 & 102 \\
\hline 14 & 95 & 94 & 162 & 133 & 162 & 138 \\
\hline 15 & 100 & 105 & 212 & 102 & 185 & 100 \\
\hline 16 & 107 & 89 & 216 & 153 & 138 & 126 \\
\hline 17 & 117 & 105 & 212 & 213 & 182 & 172 \\
\hline 18 & 95 & 104 & 209 & 162 & 141 & 121 \\
\hline 19 & 99 & 87 & 176 & 144 & 124 & 119 \\
\hline 20 & 100 & 85 & 204 & 195 & 82 & 109 \\
\hline
\end{tabular}


Figure 2. Glucose tolerance test results for the best responders to the almond preload.

a. Participant \#28

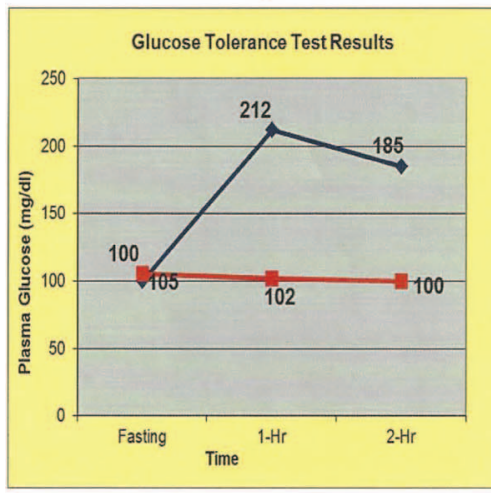

c. Participant \#2

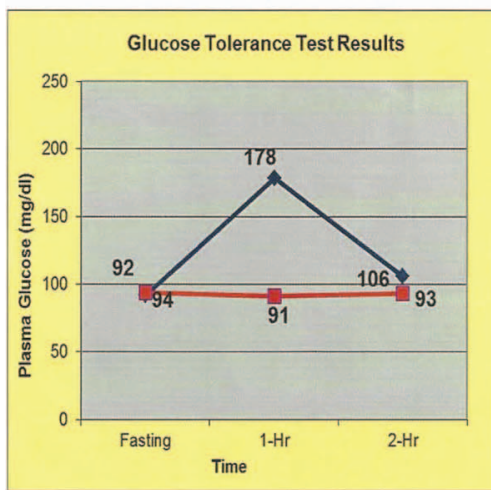

b. Participant \#11

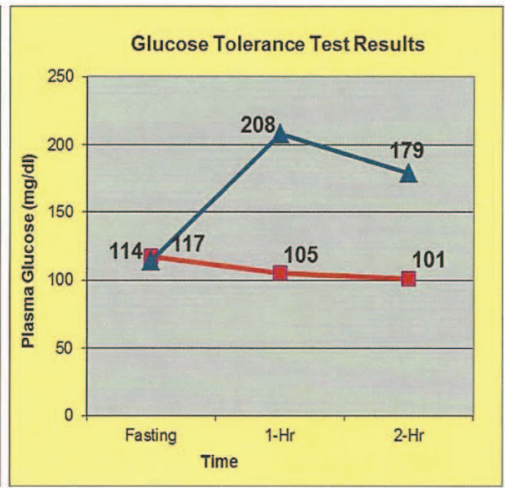

d. Participant \#4

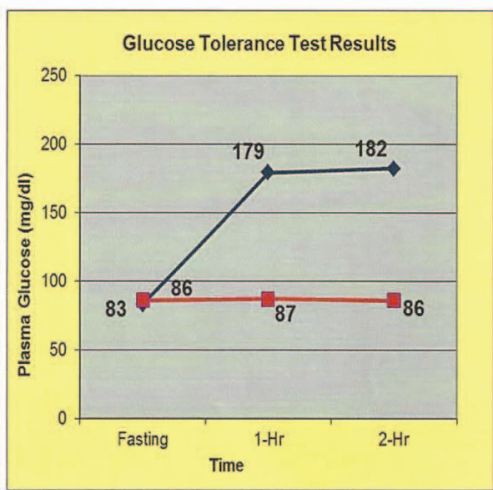

Almond ingestion reduced the AUC by $15.5 \%$ $(P<.001)$. The 12 who responded positively to the almond preload lowered their 1-hour glucose by a mean of $59 \mathrm{mg} / \mathrm{dL}(30.2 \%)$ and lowered their 2 -hour glucose by a mean of $31 \mathrm{mg} / \mathrm{dL}(21.8 \%)$. For the 8 nonresponders, the mean 1-hour glucose was only $8 \mathrm{mg} / \mathrm{dL}$ lower and the mean 2-hour glucose was $5 \mathrm{mg} / \mathrm{dL}$ higher after the almond preload. The patient characteristics showed no discernible predictors of good response with respect to age, sex, ethnicity, $\mathrm{BMI}, \mathrm{HbA}_{1 \mathrm{c}}$, insurance status, or family history of diabetes (Table 3). The only difference in the standard GTT results of responders versus nonresponders was a higher mean 2-hour glucose in responders (146 vs $126 \mathrm{mg} / \mathrm{dL}$; Table 4). Nine of the 14 participants with prediabetes responded well, whereas 3 of the 6 with isolated 1-hour glucose concentrations responded well to the almond preload.

Analysis of the dietary, exercise, and stress questionnaire data for the day before the GTTs showed no significant difference in carbohydrate intake, physical activity, or perceived stress levels before the standard versus almond GTTs (Table 1).

Three study enrollees whose standard GTT showed diabetes (mean fasting glucose, $137 \mathrm{mg} / \mathrm{dL}$; 1-hour glucose, $228 \mathrm{mg} / \mathrm{dL}$; 2-hour glucose, 225 $\mathrm{mg} / \mathrm{dL}$ ) completed the almond GTT to see whether the almond preload affected more severe glucose intolerance. None of their results were significantly different after the almond preload (mean fasting glucose, $126 \mathrm{mg} / \mathrm{dL}$; 1-hour glucose, 238 $\mathrm{mg} / \mathrm{dL}$; 2-hour glucose, $215 \mathrm{mg} / \mathrm{dL}$ ).

\section{Discussion}

Ingesting $1 / 2$ ounce of almonds 30 minutes before a GTT markedly lowered the 1-hour glucose in $40 \%$ of the participants and moderately lowered it in another $20 \%$. Almond ingestion also markedly or moderately lowered the 2-hour glucose concentration in $48 \%$, including 7 of $10(70 \%)$ of those with prediabetic GTT 2-hour values of 140 to $199 \mathrm{mg} /$ dL. The 10 participants (50\%) who had 2-hour standard GTT values $<140 \mathrm{mg} / \mathrm{dL}$ had relatively 
Table 3. Characteristics of Positive Responders to the Almond Preload*

\begin{tabular}{|c|c|c|c|c|c|c|c|c|c|}
\hline & ID & $\begin{array}{c}\text { Age } \\
\text { (years) }\end{array}$ & Sex & Race & Ethnicity & $\begin{array}{c}\mathrm{BMI} \\
\left(\mathrm{kg} / \mathrm{m}^{2}\right)\end{array}$ & $\mathrm{HbA}_{1 \mathrm{c}}$ & $\mathrm{FamHxDM}^{\dagger}$ & Insurance \\
\hline \multirow[t]{8}{*}{ Marked hypoglycemic response } & 2 & 48 & Male & White & Non-Hispanic & 25 & 5.8 & 0 & Private \\
\hline & 4 & 75 & Male & $\mathrm{AA}$ & Non-Hispanic & 33 & 6.3 & 0.5 & Private \\
\hline & 6 & 71 & Male & White & Non-Hispanic & 29 & 6.3 & 0 & Medicare \\
\hline & 11 & 46 & Male & White & Non-Hispanic & 37 & 6.1 & 0.5 & Private \\
\hline & 17 & 78 & Female & White & Hispanic & 22 & 6.3 & 0 & Medicare \\
\hline & 28 & 67 & Female & White & Hispanic & 31 & 6.0 & 1.0 & Medicare \\
\hline & 30 & 90 & Male & White & Non-Hispanic & 23 & $5.3^{1}$ & 1.5 & Medicare \\
\hline & 40 & 45 & Female & White & Hispanic & 28 & 5.9 & 0 & Medicaid \\
\hline \multirow[t]{4}{*}{ Moderate hypoglycemic response } & 4 & 67 & Female & White & Non-Hispanic & 30 & 6.4 & 0.63 & Medicare \\
\hline & 14 & 18 & Female & White & Hispanic & 36 & 6.0 & 0.75 & Uninsured \\
\hline & 19 & 70 & Male & White & Hispanic & 26 & 5.7 & 0 & Medicare \\
\hline & 20 & 38 & Male & White & Non-Hispanic & 36 & 6.3 & 0.5 & Private \\
\hline
\end{tabular}

*Random glucose of $145 \mathrm{mg} / \mathrm{dL}$ led to recruitment into the study, with a subsequent abnormal baseline glucose tolerance test.

${ }^{\dagger}$ Values for each relative: 1st degree (parent/sibling/child) $=0.5 ; 2$ nd degree (grandparent, grandchild, uncle, aunt) $=0.25 ; 3$ rd degree (1st cousin, great grandparent, great grandchild, great aunt or uncle) $=0.125$.

AA, African American; BMI, body mass index; FamHxDM, family history of diabetes.

little room for improvement in this secondary outcome variable. The mean differences between the standard GTT and the GTT after almond ingestion at 1 and 2 hours (19.4\% and $14.1 \%)$ substantially exceeded test-retest variations in serial GTT values (individual coefficient of variation, $7.8 \%){ }^{16}$

The findings support the study hypothesis that "priming the pancreatic pump" with a low-calorie preload 30 minutes before GTT significantly decreases the hyperglycemic response at 1 hour in glucose-intolerant individuals who do not have diabetes. The magnitude of the AUC reduction $(15.5 \%)$ was less than that produced by preloading with fructose and soya-yogurt (25\% to $40 \%),{ }^{8,9}$ but more than the results of the study by Tan and Mattes, ${ }^{12}$ who used a larger almond snack (1.5 vs $0.5 \mathrm{oz}) 2$ hours before testing. This almond preload was more nutritionally balanced than fructose, and it contained half the calories of the soya-yogurt

Table 4. Mean Glucose Tolerance Test Results for Those Responding to Almonds versus Nonresponders

\begin{tabular}{lcccccccc}
\hline & \multicolumn{3}{c}{ Standard GTT } & & \multicolumn{3}{c}{ Almond GTT } \\
\cline { 2 - 3 } \cline { 6 - 7 } & Fasting & 1-Hour & 2-Hour & Fasting & 1-Hour & 2-Hour \\
\hline $\begin{array}{c}\text { Responders } \\
(\mathrm{n}=12)\end{array}$ & 101 & 194 & 146 & 99 & 135 & 115 \\
$\begin{array}{c}\text { Nonresponders } \\
(\mathrm{n}=8)\end{array}$ & 99 & 188 & 126 & 95 & 183 & 125 \\
\hline
\end{tabular}

Data are mean values.

GTT, glucose tolerance test. preload and one-fourth to one-half the calories in almond meal supplementation studies. ${ }^{9,10}$

Shelled whole almonds can be conveniently carried in a ziplock bag. Almonds stay fresh for several months when stored at room temperature ${ }^{17}$ and can be eaten before workplace, fast food, or restaurant meals. The 30-minute premeal timing seems reasonably convenient. When bought in bulk (16 to $36 \mathrm{oz}$ ) a half-ounce serving of raw or roasted almonds costs 20 to 30 cents, ${ }^{18,19}$ so the almond appetizer is practical for families at most socioeconomic levels.

The main mechanism of action in those responding positively to the almond preload may be stimulation of release of stored insulin 30 minutes sooner than insulin release stimulated by the $75-\mathrm{g}$ glucose load. The slightly lower, rather than higher, glucose concentration in the first GTT sample after almond ingestion versus the standard GTT supports this notion. Other potential mechanisms include the almonds' fiber content increasing the viscosity of intestinal contents and hindering glucose diffusion, and its fat content slowing gastric emptying time, thus delaying glucose aborption. $^{12}$

The marked differences between the results of responders and nonresponders may be attributable to a variable combination of 2 factors. It seems likely that some of the nonresponders had more severely impaired production and/or release of in- 
sulin. The other plausible explanation is a greater degree of insulin resistance in some of the nonresponders.

Nonsignificant trends toward lower carbohydrate intake, more physical activity, and lower perceived stress the day before the almond GTT each should tend to neutralize the other's effect on the GTT results. Lower carbohydrate intake before a GTT tends to produce higher values on the test ${ }^{20}$ because insulin production tends to decrease when carbohydrate intake is lower. More physical activity $^{21}$ and lower perceived stress ${ }^{22}$ tend to produce lower GTT values.

\section{Limitations}

The study was conducted in a single clinical site. Although the study sample was fairly diverse with respect to ethnicity, socioeconomic, and insurance status, the sample size was relatively small, predominantly male, and mostly middle-aged or elderly. African Americans were underrepresented. No participant was extremely obese (BMI $\left.>40 \mathrm{~kg} / \mathrm{m}^{2}\right)$. It is unknown whether these findings would generalize to younger or more obese individuals.

Because the sequence of the standard and almond GTTs was not randomly varied, it is possible that the results were biased by a sequencing effect. Participants' physical activity during the GTTs was not closely monitored; bias in unobserved activity variations could have influenced the results. It would have been better to administer the stress questionnaire on the day of each GTT, rather than the day before, since perceived stress can fluctuate from day to day. The 8-ounce glass of water that was drunk only before the almond GTT and the lack of standardization of water intake during the morning hours before each GTT are potential confounders but seem unlikely to have significantly influenced the glucose results.

Plasma insulin and incretin concentrations at each of the time points in the protocol could have supported or disconfirmed the hypothesized mechanism of action. Funding constraints precluded measuring insulin or incretin concentrations.

Most blood samples were analyzed in 1 hospital laboratory, but 4 of the participants' GTT samples were analyzed by an outside commercial laboratory. Since both labs adhere to tight quality control procedures, this is unlikely to have had a significant effect on the reliability and validity of the results.
The results from 3 enrollees with diabetic standard GTT results showed no hypoglycemic effect. It is possible that studying more patients with severe glucose intolerance would show a hypoglycemic effect of the almond preload for some of them. Lovejoy et $\mathrm{al}^{23}$ found no hypoglycemic effect from supplementing the diet of 34 diabetic individuals with 57 to $113 \mathrm{~g}$ ( 2 to $4 \mathrm{oz}$ ) of almonds in meals and snacks each day for 4 weeks. Chen et $\mathrm{al}^{24}$ found that supplementation with $60 \mathrm{~g} /$ day of almonds for 3 months decreased the AUC for GTT glucose by $6 \%$.

These results raise some questions: Would a larger almond preload 30 minutes before GTT work even better? What is the optimal timing for maximizing a preload's hypoglycemic effect? What other foods would have a similar or better hypoglycemic effect? How well might the study findings translate to daily life? Will eating an almond appetizer (or similarly nutritious low-calorie snack) 30 minutes before meals lower peak postprandial glucose consistently for good GTT responders?

\section{Conclusion}

A low-calorie almond preload "appetizer" showed promise as an option for decreasing postprandial hyperglycemia in individuals with prediabetes or isolated 1-hour postprandial hyperglycemia. Further study is needed to confirm and refine the role of a premeal appetizer in the self-care of prediabetes and to investigate its potential for helping delay or avoid progression from prediabetes to diabetes.

\section{References}

1. Centers for Disease Control and Prevention. National diabetes statistics report: estimates of diabetes and its burden in the United States. Atlanta: U.S. Department of Health and Human Services; 2014.

2. Tabak AG, Jokela M, Akbaraly TN, Brunner EJ, Kiyimaki M, Witte DR. Trajectories of glycaemia, insulin sensitivity, and insulin secretion before diagnosis of type 2 diabetes: an analysis from the Whitehall II study. Lancet 2009;373:2215-21.

3. Diabetes Prevention Program Research Group. 10Year follow-up of diabetes incidence and weight loss in the Diabetes Prevention Program Outcomes Study. Lancet 2009;374:1677-86.

4. Kahn SE. The importance of $\beta$-cell failure in the development and progression of type 2 diabetes. J Clin Endocrin Metab 2001;86:4047-58.

5. Fantus G. Glucose toxicity. In: De Groot LJ, Chrousos G, Dungan K, et al, eds. Diabetes endotext. South Dartmouth, MA: MD Text.com, Inc.; 2000. 
Available from: www.ncbi.nlm.nih.gov/books/ NBK278934/. Accessed February 23, 2016.

6. Gerich JE. Is reduced first-phase insulin release the earliest detectable abnormality in individuals destined to develop type 2 diabetes? Diabetes 2002; 51(Suppl 1):117-21.

7. Abdul-Ghani MA, DeFonzo RA. Plasma glucose concentration and prediction of future risk of type 2 diabetes. Diabetes Care 2009;32:S194-8.

8. Heacock PM, Hertzler SR, Wolf BW. Fructose prefeeding reduces the glycemic response to a highglycemic index, starchy food in humans. J Nutr 2002; 132:2601-4.

9. Chen MJ, Jovanovic A, Taylor R. Utilitizing the second-meal effect in type 2 diabetes: practical use of a soya-yogurt snack. Diabetes Care 2010;33:2552-4.

10. Josse AR, Kendall CW, Augustin LS, Ellis PR, Jenkins DJ. Almonds and postprandial glycemia-a doseresponse study. Metabolism 2007;56:400-4.

11. Jenkins DJ, Kendall CW, Marchie A, et al. Almonds decrease postprandial glycemia, insulinemia, and oxidative damage in healthy individuals. J Nutr 2006; 136:2987-92.

12. Tan SY, Mattes RD. Appetitive, dietary and health effects of almonds consumed with meals or as snacks: a randomized controlled trial. Eur J Clin Nutr 2013; 67:1205-14.

13. Cohen S, Janicki-Deverts D. Who's stressed? Distributions of psychological stress in the United States in probability samples from 1983, 2006 and 2009. J Appl Soc Psychol 2012;42:1320-34.

14. US Department of Agriculture, Agricultural Research Service, Nutrient Data Laboratory. USDA National Nutrient Database for Standard Reference, release 28. Last modified August 13, 2016. Available from: http://www.ars.usda.gov/Services/docs.htm? docid=8964. Accessed September 29, 2016.
15. My Fitness Pal [homepage]. Available from: https:// www.myfitnesspal.com/. Accessed September 29, 2016.

16. Kosaka K, Mizuno Y, Kuzuya T. Reproducibility of the oral glucose tolerance test and the rice-meal test in mild diabetics. Diabetes 1966;15:901-4.

17. Cornacchia R, Amodio ML, Colelli G. Effects of storage temperature and duration on quality of unshelled and shelled almonds. Acta Hortic 2012;934: 783-90.

18. Sam's Club. Fruit \& nuts. Available from: http:// www.samsclub.com/sams/fruit-nuts/2259.cp. Accessed April 6, 2016.

19. Amazon.com. Natural raw almonds (4 pound bag). Available from: http://www.amazon.com/NaturalRaw-Almonds-Pound-Bag/dp/B001ESHOA6. Accessed April 6, 2016.

20. Caminhotto RDO, Lima FB. Impaired glucose tolerance in low-carbohydrate diet: maybe only a physiological state. Amer J Physiol Endocrin Metab 2013;305:E1521.

21. Short KR, Pratt LV, Teague AM. The acute and residual effect of a single exercise session on meal glucose tolerance in sedentary young adults. J Nutr Metab 2012;2012:278678.

22. Dungan KM, Braithwaite SS, Preiser JC. Stress hyperglycaemia. Lancet 2009;373:1798-807.

23. Lovejoy JC, Most MM, Lefevre M, Greenway FL, Rood JC. Effect of diets enriched in almonds on insulin action and serum lipids in adults with normal glucose tolerance or type 2 diabetes. Am J Clin Nutr 2002;76:1000-6.

24. Chen CM, Lin JF, Huang CL, et al. Effect of almonds on glucoregulation and CVD risk factors in patients with type 2 diabetes. FASEB J 2015;29(1 Suppl):912.3. 